\title{
Un caso práctico para el análisis del neuromarketing visual en el Centro Comercial Ventura Plaza (Cúcuta, Colombia)
}

\author{
A case study for the analysis of visual neuromarketing in Plaza Ventura (Cucuta-Colombia)
}

Un cas pratique pour l’analyse du neuromarketing visuel dans le centre commercial Ventura Plaza (Cúcuta, Colombie)

\author{
William R. Avendaño Castro \\ Docente Investigador, Director Grupo de Investigación en \\ Responsabilidad Social (GIRS), Universidad Francisco de Paula \\ Santander, Cúcuta - Colombia. \\ Magister en Administración, Universidad Santo Tomás. \\ E-mail:wrac2008@hotmail.com \\ Artículo de investigación científica y tecnológica \\ según clasificación COLCIENCIAS \\ Recepción: 20/02/2013 \\ Corrección: $13 / 03 / 2013$ \\ Aprobación: 25/04/2013
}

\section{Resumen}

Los avances en las áreas de la psicología, la neurociencia, el ámbito cognitivo y la comprensión sobre el funcionamiento del cerebro humano han posibilitado que otras disciplinas y áreas del conocimiento formulen nuevas teorías. Este es el caso del marketing, que haciendo uso de los últimos descubrimientos a nivel cerebral, ha incorporado estrategias para la captación de clientes. Se hace una revisión de las prácticas visuales de neuromarketing de 124 establecimientos del Centro Comercial Ventura Plaza, el más importante de la ciudad de Cúcuta (Norte de Santander, Colombia). La muestra estuvo representada por 71 establecimientos de textiles, 25 de comidas, 12 de electrodomésticos, 11 de diversión y entretenimiento y 5 de libros. Se aplicó una matriz que recopiló la información sobre la imagen externa e interna de los establecimientos atendiendo al uso del color, la luz y la imagen fotográfica. Los resultados muestran que un buen porcentaje de los establecimientos aplican los principios del neuromarketing asociados con la percepción sobre el color, la luz y la imagen fotográfica.

Palabras clave: neuromarketing, neurociencia, marketing, cerebro, percepción visual.

\begin{abstract}
Progress in psychology, neuroscience, and cognitive fields and comprehension of the functioning of the human brain has enabled other disciplines and areas of knowledge to formulate new theories. This is the case of marketing, which by using recent discoveries at cerebral level has incorporated strategies to attract clients. The article is a review of the practices of 124 visual neuromarketing establishments at Ventura Plaza Mall, the largest in the city of Cucuta (Norte de Santander, Colombia). The sample was represented by 71 textile establishments, 25 food vendors, 11 entertainment establishments, five book stores, and 12 appliance stores. The aforementioned was applied to a matrix compiling information on the external and internal image of establishments serving the use of color, light, and photographic images. The results show that a good percentage of the establishments apply neuromarketing principles associated with the perception of color, light, and photographic images.
\end{abstract}

Keywords: neuromarketing, neuroscience, marketing, brain, visual perception.

\section{Résumée}

Les progrès dans les domaines de la psychologie, la neuroscience, l'ambiance cognitive et la compréhension du fonctionnement du cerveau humain ont fait possible que d'autres disciplines et aires de la connaissance formulent de nouvelles théories. C'est le cas du marketing, qui faisant usage des dernières découvertes à niveau cérébral, a incorporé des stratégies pour la captation de clients. On fait une révision des pratiques visuelles de neuromarketing de 124 établissements du centre commercial Ventura Plaza, le plus important de la ville de Cúcuta (département de Norte de Santander en Colombie). L'échantillon a tenu compte de 71 établissements textiles, 25 de nourriture, 12 d’appareils électroménagers, 11 d’amusement et de divertissement et 5 de livres. On a appliqué une matrice qui a recompilé l’information sur l’image externe et interne des établissements tenant compte l’usage de la couleur, la lumière et l’image photographique. Les résultats montrent qưun haut pourcentage des établissements appliquent les principes du neuromarketing associés à la perception sur la couleur, la lumière et l’image photographique. 


\section{Introducción}

El siglo XXI representa una cadena de desafíos para los empresarios, profesionales en marketing y aquellos quienes se encuentran relacionados con la oferta, promoción y comercialización de productos. Las fuerzas sociales han conducido a un cambio en el marketing, fenómeno marcado por diversos factores como la globalización, el desarrollo tecnológico, la desregularización, la privatización, la personalización, y otros (Kotler y Keller, 2006, p. 13-14). El presente entorno requiere de herramientas para posicionar y liderar el mercado, porque este es altamente competitivo en todos los ámbitos (Pavón y Hidalgo, 1999) y se requiere asumir la difícil tarea de mantenerse, sin permitir que los entes competidores lo debiliten u opaquen. En este marco, el área de mercadeo se halla en permanente transformación porque percibe que se requiere de herramientas efectivas para ubicar sus productos o servicios en los primeros lugares en ventas (Ferrell y Hartline, 2006, p. 1), porque si se logran estas características, los beneficios para el equipo organizacional de la empresa o ente comercial, serán más altos (Morales y Rivera, 2012, p. 7).

Según Ferrer (2009, p. 9) la gestión del cambio constante es uno de los retos primordiales del mercado actual debido a que los clientes se encuentran en medio de un mercado versátil, saturado de productos y mensajes, que implica cambios económicos, sociales, políticos y culturales, obligando a las empresas a adaptarse al nuevo panorama y a las circunstancias que se presentan. Es así, como los consumidores viven en una sociedad con acceso a muchas ofertas de productos y servicios con precios similares, que gracias a los avances tecnológicos, facilitan el modo de vida de los clientes y los usuarios, lo que conduce a que las decisiones de elección sean cada vez más complejas (Alvarado, 2008).

La investigación de mercado evoluciona de forma continua, incorporando nuevas técnicas y enfoques (Kinnear y Taylor, 1998). Para Ferrer (2009, p. 9), la imagen y la identidad bien elaboradas y gestionadas conceden a la organización y a sus productos permanencia en el mercado a través del tiempo. Esto posiciona a la empresa en la mente del consumidor y ayuda a marcar diferencias con la competencia. Gracias a esto, el neuromarketing se plantea como una de las tendencias eficaces para el movimiento del mercado (Penn, 2011), representando un verdadero "giro neurocéntrico" (García-Marza, 2012, p. 55).

La neurociencia desde la perspectiva del marketing estudia las emociones del consumidor a partir de sus hábitos de consumo y la reacción que tiene ante los distintos estímulos que brinda la publicidad. Muchas de las decisiones de los consumidores se centran en sensaciones netamente subjetivas y estas, a su vez, se encuentran ligadas con los estímulos sensoriales que se activan en el momento de consumo (Tamblay, 2011, p.
34-35). Es así, como el neuromarketing es la aplicación de las técnicas de la neurociencia, para la comprensión de la dinámica cerebral ante los estímulos del marketing:

La aplicación de métodos neurocientíficos al análisis, la comprensión y descripción de los comportamientos humanos relacionados con el consumo, su implicación en el mercado y las aplicaciones de estos conocimientos al marketing dan cuenta de un hecho real, y es que el comportamiento de consumo no se reduce a una situación binaria, de corte sociológico, en la que se da una respuesta a un estímulo, o acaso una relación simple de causa y efecto exclusivamente, tal como se considera desde la investigación tradicional en marketing (Salazar, 2011, p. 146).

Para Kenning y Plasman (2005) la finalidad de este tipo de herramienta es comprender cómo los sistemas sensoriales del cerebro transforman la información captada del mundo externo y la traduce por medio del sistema nervioso a una cantidad de estímulos a los que está expuesto un individuo al lenguaje del cerebro, es decir, la transmisión de la información. El neuromarketing investiga cómo responde el cerebro humano frente a los estímulos en el comportamiento del consumidor, al elegir una marca, al comprar algún producto o al interpretar los mensajes que recibe del exterior.

En épocas pasadas, era complejo examinar los mecanismos cerebrales destinados al funcionamiento de los sentimientos, emociones, recuerdos, percepciones y aprendizaje que fijan el comportamiento del consumidor (Braidot, 2005). En la actualidad, gracias a las investigaciones originadas de las neurociencias, se ha logrado comprender y mejorar los procesos en la toma de decisiones y la conducta de los clientes frente al consumo de bienes y servicios. Es así, como el neuromarketing es una herramienta poderosa con la que las empresas actuales cuentan para capturar la atención de sus consumidores.

El objetivo de este artículo es identificar las prácticas de neuromarketing presentes en 124 establecimientos comerciales del Centro Comercial Ventura Plaza del municipio de Cúcuta, divididos en las categorías de textiles, comida, diversión-entretenimiento, libros y electrodomésticos, analizando las estrategias visuales para la captación de clientes a partir de una matriz de observación diseñada para tal fin.

\section{Marco teórico}

\subsection{Marketing y neuromarketing}

El marketing desde sus comienzos, se ha nutrido de los conocimientos de disciplinas como la economía, psicología, sociología, antropología, entre otras. Al introducir la neurociencia dentro de este parámetro de conocimiento, se dio paso a una evolución amplia que condujo a la creación de lo que se conoce con el nombre 
de neuromarketing (Kenning y Plasman, 2005). Esta evolución trajo consigo el desarrollo de metodologías novedosas para la comprensión del funcionamiento del cerebro y con esto, la explicación de los procesos clave para la toma de decisiones frente al consumo de servicios y productos, con el fin de crear e implementar estrategias para impulsar el crecimiento. Así, el neuromarketing es una técnica desarrollada con el objeto de explorar la respuesta del cerebro humano a los estímulos y dar a conocer con mayor precisión a las organizaciones los deseos, gustos, motivaciones y necesidades de compra de los consumidores (Ferrer, 2009).

Según Kenning y Plasman (2005), el neuromarketing tiene inmerso un conjunto de recursos de gran valor para investigar, segmentar y desarrollar el mercado a partir de estrategias en materia de productos, ya sea de diseño o marca, para dar un posicionamiento al mismo acorde con sus precios, canales de comunicación, entre otros. El neuromarketing se define ante todo, como una herramienta o tendencia del marketing que:

[...] investiga y estudia los procesos cerebrales que explican la conducta y la toma de decisiones de las personas en los campos de acción del marketing tradicional como la inteligencia de mercado, diseño de productos y servicios, comunicaciones, precios, branding, posicionamiento, targeting, canales y ventas (Braidot, 2011, p. 16).

La finalidad del neuromarketing es utilizar conocimientos enfatizados en los procesos cerebrales frente a los estímulos, para optimizar la dinámica de las decisiones de los consumidores frente a los productos y servicios. Dentro de los objetivos más importantes que destaca el neuromarketing se encuentran entre otros: (i) hacer uso del conocimiento en torno al sistema nervioso y su respuesta a los estímulos, (ii) determinar la efectividad de la publicidad, (iii) seleccionar formatos de medios en coherencia con los objetivos, (iv) estudiar la mente del consumidor en función de su conducta, (v) mejorar la planificación estratégica (Ferrer, 2009, p. 54).

Los objetivos del neuromarketing son muy variados y van desde la comprensión de la actividad cerebral frente a los estímulos del diseño de campañas publicitarias hasta la evaluación de la efectividad de las mismas estrategias. Sobre el campo de investigación propio del neuromarketing se ha gestado gran variedad de literatura que incluye teorías en torno al tema. Se revisan algunas de ellas a continuación.

\subsection{Los seis únicos estímulos que llegan al cerebro decisivo}

En el amplio ámbito del neuromarketing, Morin (2006) citado por Ferrer (2009) expone una teoría que sustenta que las decisiones de los sujetos son producto del cerebro decisivo o primitivo previo procesamiento de la información en relación con las emociones que experimenta.
Fundamentado en esto, Ferrer (2009) expone que Morin (2006) se centra en el aprendizaje basado en el estudio de la experiencia pasada y define seis principios que explican el funcionamiento del cerebro decisivo del consumidor:

a. el cerebro del ser humano está centrado en sí mismo

b. el cerebro primitivo es sensible al contraste

c. el cerebro tiene necesidad de información tangible

d. el cerebro recuerda de manera selectiva

e. el cerebro se inclina con mayor fuerza a los estímulos visuales, y

f. el cerebro se dispara fuertemente con la emoción.

El primer principio significa que las decisiones de los consumidores tienen su fuente en el subconsciente, que está marcado por la necesidad de satisfacer el bienestar y la supervivencia. El segundo principio, menciona que es fundamental marcar una diferencia frente a la competencia a través del mensaje que se quiere transmitir. El tercer principio aborda la necesidad de transmitir un mensaje desde lo concreto en donde se facilite la comprensión e interpretación del mismo, esto es, disminuir los niveles de abstracción. El cuarto principio ahonda en que el cerebro aprende con mayor efectividad un mensaje narrado del cual se recuerda el principio y el final. El quinto principio hace énfasis en el potencial que tienen los mensajes visuales, porque estos son más fáciles de comprender y asimilar. Por último, el sexto principio afirma que las emociones generan procesos químicos que dan un criterio de interpretación a la información que se transmite, permitiendo la memorización del mensaje.

\subsection{El cerebro: los tres niveles principales}

El $85 \%$ del peso total del cerebro está constituido por los hemisferios cerebrales. Las neuronas allí situadas, se encuentran conectadas por un denso manojo de nervios que recibe el nombre de cuerpo calloso. Los estudios científicos demuestran que los dos hemisferios difieren entre sí según el modo en cómo procesan la información (Pride y Ferrell, 2006, p. 243). Los hemisferios cerebrales comprenden una capa exterior denominada corteza cerebral, en donde se procesa la información sensorial percibida del mundo exterior, controla los movimientos voluntarios y además, regula el pensamiento consciente y la actividad mental (Pride y Ferrell, 2006, p. 243) (Figura 1).

El hemisferio izquierdo se centra en los detalles, como el reconocer un rostro particular en medio de una multitud. Por otra parte, el hemisferio derecho se enfoca en las generalidades, en comprender la posición relativa de los objetos en el espacio. Cada hemisferio del cerebro se divide en cuatro lóbulos (Carter, 1998 citado por Ferrer, 2009, p. 16-17): 
a) lóbulo occipital, que se encarga del procesamiento visual y se encuentra ubicado en la parte posterior; b) lóbulo temporal, ubicado en la parte inferior (cerca de los oídos). Cumple las funciones relacionadas con el sonido, la comprensión del habla (en el lado izquierdo) y algunos aspectos relacionados con la memoria; c) lóbulo parietal, se ocupa de las funciones relacionadas con el movimiento, la orientación, el cálculo y ciertos tipos de reconocimiento. Se encuentra en la sección superior; d) lóbulo frontal, ubicado delante del lóbulo parietal. Lleva a cabo las funciones cerebrales más integradas, como pensar, asimilar e incorporar conceptos y la planificación. Además, desempeña una función importante en el registro consciente de las emociones.

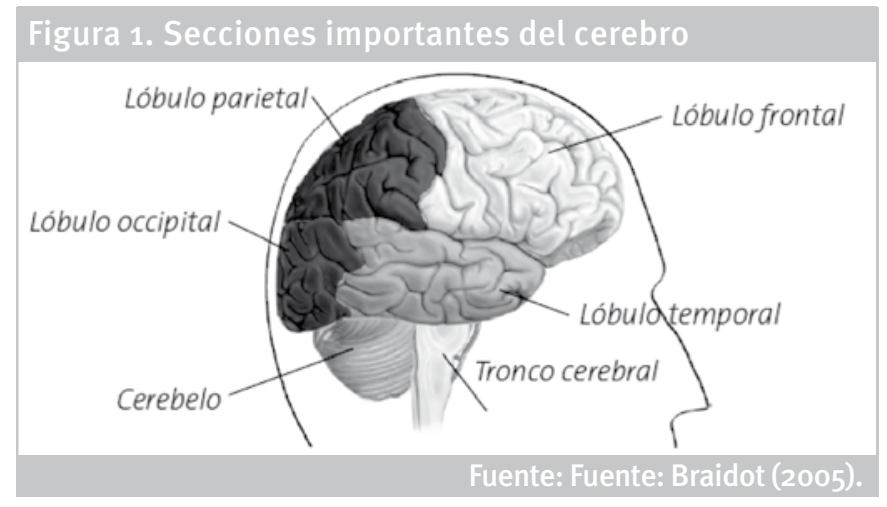

El cerebelo abarca un poco más del $10 \%$ del cerebro y es el encargado del equilibrio y la coordinación. Este también comprende dos hemisferios que reciben información de los ojos, oídos, músculos y articulaciones, es decir, se centra en los movimientos y la posición del cuerpo. Una vez procesada esta información por el cerebelo, esta viaja a través del resto del cerebro y médula espinal para dar instrucciones al cuerpo. Gracias a la labor del cerebelo, se logra caminar sin tropiezos, dar vueltas sin pensar hacerlo y mantener el equilibrio general del cuerpo.

Renvoisé y Morin (2007) exponen que otra parte importante es el tallo cerebral, ubicado en la base del cerebro. Este conecta la médula espinal con las otras partes del cerebro. Aunque es el más pequeño de los tres niveles más importantes, sus funciones son primordiales para la supervivencia, porque controla las funciones automáticas que mantiene vivo el cuerpo, la frecuencia cardíaca, la presión arterial y la respiración. Además transmite información a los músculos, piel y otros órganos a través de la conexión cerebro-médula espinal. El tallo cerebral también controla el descanso y el sueño.

\subsection{El cerebro: otras partes de importancia}

El cerebro también comprende otras partes primordiales ubicadas en el interior de los hemisferios nombrados antes, por ejemplo, el sistema límbico o visceral y el tálamo. El primero, conecta el tallo cerebral con los distintos elementos de razonamiento y comportamiento instintivo, además aquí se encuentra ubicado el sentido del olfato. El hipocampo es esencial en el proceso de aprendizaje y de la memoria a corto plazo. Se considera el sitio donde los recuerdos a corto plazo se convierten en recuerdos a largo plazo y luego son guardados en otras partes del cerebro (Ferrer, 2009, p. 26).

El tálamo recibe la información límbica y sensorial, la procesa para luego enviarla a la corteza cerebral. El hipotálamo, es una estructura ubicada bajo el tálamo, que se encarga de la temperatura corporal y el consumo de alimentos. Además, al igual que el hipotálamo, controla el reloj interno del cuerpo y corrige desajustes.

\subsection{Las neuronas, su actividad y efectos}

La comunicación entre las neuronas se da con la formación de grandes redes que procesan y transmiten la información por medio de la sinapsis. Existe un espacio pequeño que separa a las neuronas entre sí, llamado sinapsis, en donde se generan los impulsos y se desencadena un proceso eléctrico. Es de importancia comprender que las neuronas forman redes para entender la complejidad de los fenómenos cerebrales y mentales como el aprendizaje, la percepción, el procesamiento de la información y la memoria. Braidot (2005) menciona que las neuronas generan la actividad cerebral, las cuales se encuentran interconectadas a través de los axones y las dendritas. Los primeros conducen las señales y las segundas reciben la información, y a este proceso se le conoce como sinapsis en donde cada axón se encuentra con una dendrita a través de una ranura.

Frente a estímulos de información o cualquier tipo de experiencia, se genera una activación cerebral que produce una conexión neural. Si el estímulo es fuerte 0 se repite constantemente, la sinapsis se precipita y se forman redes que se relacionan entre sí. De este modo, acorde con las experiencias que se van acumulando, el entramado neuronal se aumenta y adopta mayor complejidad, es decir, el cerebro se encuentra en una reconexión constante en función con las experiencias cotidianas. Para Khalfa (1995) las decisiones de las personas están marcadas por las vivencias experimentadas a través de la existencia y que se materializan en el cerebro del individuo a través de una red neuronal que implica su aprendizaje, memoria e inteligencia.

El cerebro se asimila a un conjunto de circuitos que se interconectan entre sí, en donde cada neurona excita a las cercanas y éstas a las demás. Por lo tanto se crea un acondicionamiento adecuado para producir actividades como la memoria, las emociones y el comportamiento, aspectos que pueden ser tomados en consideración por el neuromarketing. 


\subsection{Principios de percepción: la luz}

La luz es una forma de energía y puede ser natural o artificial. En el primer caso es producida por el sol o la luna y en el segundo es originada por la acción del hombre. En los dos casos, la luz actúa sobre el ojo del ser humano haciendo que este perciba de forma visual los objetos (Malfitano, 2007). Con esto, las teorías físicas argumentan que los cuerpos opacos se ven iluminados, manteniendo la propiedad de absorber la luz recibida o parte de ella. En efecto, los objetos muestran las radiaciones propias a su color, es decir, que la luz es la que evidencia los colores pero no los objetos.

Fraser y Banks (2005) mencionan que en la representación de una imagen, hay que considerar la calidad y cantidad de luz ambiental. En el caso de la publicidad exterior, hay que tomar como eje la iluminación de todas las partes del anuncio, como las luces y sombras, y de este con su alrededor; también, el papel del color de la luz ambiental con el de la superficie del anuncio, es decir, la vista del transeúnte con las propiedades reflectantes (Tabla 1).

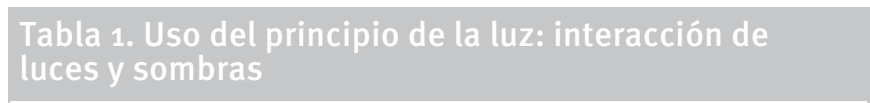

La sombra de un objeto incluye el complementario del color del objeto.

El uso de luces cálidas (amarillo/rojo), proyecta sombras frías. El uso de luces frías (azul/verde) proyecta sombras cálidas.

La iluminación simultánea de un objeto con luces de distintos colores, resulta sorprendente.

El color de la luz artificial varía de acuerdo con los componentes que se calientan. En verbigracia una luz artificial naranja es producida cuando el haz contiene calcio; una luz amarilla, el haz posee sodio; una luz artificial roja, el haz se encuentra compuesto por gas neón.

El aspecto de una imagen iluminada con luz verde, roja y azul le provee un aire más sutil, que iluminada con luz natural o artificial.

Fuente: Fraser y Banks (2005).

Fraser y Banks (2005) afirman que es relevante considerar la cantidad y posición de la luz en el tema de la publicidad exterior, en situaciones tanto diurnas como nocturnas. En relación con la cantidad de la misma, es importante el estudio de las dimensiones de color como el tono, la saturación y el valor, en conjunto con el ángulo y ubicación del proceso visual del transeúnte.

En relación con lo anterior, Raydan (2003) parafraseado por Vera (2010, p. 161) comenta que el "emplazamiento de la luz, ya sea en sentido natural o artificial, le imprime al motivo trabajado características de iluminación particulares, las cuales destacan ciertos aspectos de la imagen mientras opacan otros". Es claro que el problema actual de la publicidad exterior se halla en la disposición de los anuncios respecto de la luminosidad diurna o nocturna, por lo que es de gran valor la realización de un estudio previo del sitio y espacio donde se dispondrá la publicidad en relación con el mensaje y target.

\subsection{Principios de percepción: el color}

En relación con el color, Vera (2010, p. 162) citando a Malfitano (2007) define al color de un modo físico y psicológico. Desde el punto de vista físico, hace referencia a "[...] la calidad de los fenómenos visuales depende de la impresión diferente que producen en los ojos, las luces de distintas longitud de onda", es decir, el color varía según la naturaleza de los rayos de luz y el modo en que la luz se refleja. Por tanto, el color es inexistente y se manifiesta a través de la luz.

Por el contrario, la definición del color desde una perspectiva psicológica, ha de referirse a un estado de conciencia del ser humano, donde al observarse un color se retransmite un impulso a los órganos visuales que provocan alteraciones químicas y reacciones en ellos. A su vez, estas reacciones producen impulsos nerviosos al cerebro que lo impresionan de alguna forma (Malfitano, 2007, p. 136). Siendo así, el color es intangible y una sensación subjetiva propia de cada individuo. Por otra parte, Vanel (1990) citado por Guanipa (2007, p. 74) expone que:

El lenguaje de los colores significa, sencillamente, que estos no solamente se supeditan a representar la realidad en imagen, sino que también pueden hablar y por supuesto mentir, significan que los colores devienen un código y que, por consiguiente, cada color es un signo que posee su propio significado.

Los colores son tan numerosos como las emociones. En esta concepción de los colores, se concluye lo siguiente (Malfitano, 2007, p. 146):

a) [...] los colores generan diferente influencia en las personas; b) la recepción de los colores a través del sistema visual, provoca emociones o sensaciones al igual que el odio al escuchar música; c) por influencia del color, se ahondan o surgen sentimientos tan diferentes como la tristeza o la alegría, la calma o la agresividad, la cólera o la agitación; en definitiva, los colores nos modifican el estado de ánimo.

El color ha contribuido a expresar palabras con significados visuales. Para Fraser y Banks (2005) cualquier medio publicitario se basa en el color para transmitir el mensaje. La elección del color depende de los factores psicológicos con fines de generar impacto. Con base en esto, los autores definen características determinadas para los colores más usuales en la publicidad (Tabla 2).

En cuanto a los parámetros para el uso adecuado del color, Fraser y Banks (2005) citados por Vera (2010) definen los siguientes principios a considerar: 


\begin{tabular}{|c|c|}
\hline Color & Caracterización \\
\hline Rojo & $\begin{array}{l}\text { * Es más usado por la mujer que por el hombre. Al } \\
\text { hombre le atrae el maquillaje (lápices labiales, } \\
\text { punturas faciales, esmaltes de uñas) y la ropa de } \\
\text { color rojo en una mujer. } \\
\text { * Es el color de la vida. } \\
\text { * Percepción inicial. Aporta a la decisión el punto de } \\
\text { vista emocional. } \\
\text { * Trasfondo de miedo, odio, ira, celos, amor. } \\
\text { * Combinado con el amarillo produce saciedad, } \\
\text { hambre y estrés visual. } \\
\text { * Avisos luminosos. } \\
\text { * Usado en las salas de cine y de teatro. } \\
\text { * No usado en ambiente de trabajo, porque fomenta } \\
\text { discusiones e incrementa las reacciones emotivas. } \\
\text { * El magenta atrae un mercado joven. } \\
\text { * Señala la etapa infantil (o a } 20 \text { años) en el ciclo de } \\
\text { vida humana. }\end{array}$ \\
\hline Amarillo & $\begin{array}{l}\text { * Es el color de mayor impacto para la retina humana. } \\
\text { Promueve la acción. } \\
\text { * Generación de propuestas positivas. Aspectos } \\
\text { generativos del pensamiento. } \\
\text { * Cubre desde un espectro lógico y práctico para los } \\
\text { sueños. } \\
\text { * El exceso de optimismo conduce al fracaso. } \\
\text { * Disminuye el color rojo y absorbe el frío del azul. } \\
\text { * Para elementos que se identifiquen con la seguri- } \\
\text { dad personal y en las personas. } \\
\text { * Hace que los objetos se vean de mayor tamaño. } \\
\text { * Recordatorio de vacaciones. } \\
\text { * Color de la alegría. } \\
\text { * Sugiere aire natural y campesino combinando } \\
\text { naranja, verdes y marrones. } \\
\text { * El amarillo claro evoca productos de lechería y los } \\
\text { ocres productos saludables. } \\
\text { * Nuevos productos. } \\
\text { * Señala la etapa de madurez ( } 42 \text { a } 63 \text { ) en el ciclo de } \\
\text { vida humano. }\end{array}$ \\
\hline Azul & $\begin{array}{l}\text { * El hombre en el occidente se viste de azul. La mujer } \\
\text { lo hace solo para controlar al hombre. } \\
\text { * Es un color popular. } \\
\text { * Brilla por su ausencia en el reino animal y vegetal. } \\
\text { * Evaluación y control. } \\
\text { * Provee constancia y seguridad, por lo que es usado } \\
\text { en medios de transportes y finanzas. } \\
\text { * Desarrollo de metodologías } \\
\text { * Naturalmente no se asocia con a la comida. } \\
\text { * Determina el foco de atención. } \\
\text { * Comunica y media. } \\
\text { * Uso general para la escritura y los uniformes. } \\
\text { * Regenerador del vitalismo corporal y mental. } \\
\text { Medicina preventiva. } \\
\text { * La luz azul disminuye la tensión muscular y } \\
\text { nerviosa. } \\
\text { * Adecuado para evitar la discusión, ideal para } \\
\text { conciliaciones. } \\
\text { * Usado en productos de limpieza facial por su repre- } \\
\text { sentación con el agua. } \\
\text { * Relacionado con los viajes. } \\
\text { * Asociado con el amarillo produce una sensación } \\
\text { veraniega. } \\
\text { * Señala la etapa de vejez (63 y más) en el ciclo de } \\
\text { vida humano. }\end{array}$ \\
\hline Verde & $\begin{array}{l}\text { * Desarrollo de nuevas ideas, fomenta la creatividad } \\
\text { y la innovación. } \\
\text { * Carácter y efecto prospectivo, visión de futuro. } \\
\text { * Es acción, es una expresión de actividad. } \\
\text { * Es el color más fácil de percibir por el ojo humano. } \\
\text { * Lámparas de dormitorios para procurar mayor }\end{array}$ \\
\hline
\end{tabular}

\begin{tabular}{|c|c|}
\hline Naranja & $\begin{array}{l}\text { descanso. } \\
\text { * Usado en casas de salud y sanatorios. } \\
\text { * Estimula y recopila. } \\
\text { * Verde claro es aceptado. Verde oscuro es } \\
\text { rechazado por el } 90 \% \text { de la gente. } \\
\text { * Señala la etapa de juventud ( } 20 \text { a 42) en el ciclo de } \\
\text { vida humano. } \\
\text { * Color del ciclo vegetal, primaveral y de la fertilidad. } \\
\text { * Festividades. } \\
\text { * Recomendado en ambientes de personas apáticas. }\end{array}$ \\
\hline Violeta & $\begin{array}{l}\text { * Color de la vejez senil. } \\
\text { * Predilecto por los jóvenes. } \\
\text { * Luces nocturnas. } \\
\text { * En avisos las letras violetas resaltan sobre fondos } \\
\text { amarillos o naranjas. } \\
\text { * Aplicado en juguetes y cosméticos. } \\
\text { * Combinado con el verde produce una sensación } \\
\text { extraña desagradable. } \\
\text { * Combinado con el oro, produce una sensación de } \\
\text { alto impacto y de poder. } \\
\text { * No es conveniente usar en combinación con o sobre } \\
\text { azul, rojo y gris. }\end{array}$ \\
\hline Blanco & $\begin{array}{l}\text { * En detergentes, jabones y blanqueadores. } \\
\text { * Higiene en general. } \\
\text { * Guía de dirección para localizar información. } \\
\text { * Es creíble, da por sentado un hecho. } \\
\text { * Soporte de información necesaria para la toma de } \\
\text { decisiones. }\end{array}$ \\
\hline Negro & $\begin{array}{l}\text { * No recomendable para alimentos. } \\
\text { * Aumenta el contraste de colores claros. } \\
\text { * Envases negros para mercancías selectas, de alta } \\
\text { calidad. } \\
\text { * El negro connota sexualidad. } \\
\text { * Señala riesgos, peligros. } \\
\text { * Formula preguntas negativas. }\end{array}$ \\
\hline Gri & $\begin{array}{l}\text { * El gris se asocia con a productos duraderos, fiables, } \\
\text { de alto valor utilitario y discretamente sofisticado. } \\
\text { * Papel importante en el diseño de calle. } \\
\text { * Su neutralidad se presta como aplicación minima- } \\
\text { lista del color. }\end{array}$ \\
\hline & $\begin{array}{l}\text { nte: Malfitano (2007); Russell (1990a); Russell } \\
\text { (1990b); Russell (1990d), Russell (1990C) }\end{array}$ \\
\hline
\end{tabular}

a. Relación figura-fondo: Predisposición a observar figuras oscuras con fondos iluminados.

b. Uso de colores cálidos (tonos rojos, amarillos y naranjas) los cuales permiten acercar al consumidor. Los tonos fríos (azules, verdes, morados) tienen un efecto distanciador.

c. Las figuras oscuras sobre fondos oscuros hacen sobresalir los objetos.

d. Los elementos diferenciados al fondo atraen la mirada.

e. Las formas deben ser grandes y cálidas respecto de las figuras del fondo.

f. Las secuencias cromáticas dan un método de observación al sujeto, haciendo de la imagen más dinámica. 


\subsection{Principios de percepción: la imagen fotográfica}

"Una imagen vale más que mil palabras", mencionan Renvoisé y Morín (2007), para referirse a que la vista, entre todos los sentidos, es la que accede con mayor rapidez al cerebro. Los autores exponen que el cerebro primitivo registra las imágenes mucho antes que el cerebro nuevo las reconozca y analice. El mejor componente para llegar al cerebro primitivo de un cliente potencial es la imagen visual en forma de fotografía panorámica. Según Guanipa (2007), las imágenes fotográficas se presentan como recursos de gran valor e importancia en la comunicación visual, en especial en la publicidad al destacar el producto realzándolo a través de fondos, técnica de los planos, manejo de las escalas dimensionales y volumétricas de la imagen y la utilización de efectos escénicos que obligan al cliente a mirar.

Barthes (1986), menciona que la fotografía contiene inmersos dos mensajes, el mensaje denotado que es el propio análogo y un mensaje connotado que es el modo en que la sociedad ofrece su opinión sobre este. Considerando lo expuesto por Renvoisé y Morin (2007) referente a la fotografía panorámica, mencionan que las imágenes visuales con contraste son mucho más efectivas, pues requieren del uso de dos imágenes: la primera muestra la vida del cliente sin el producto o servicio, mientras que en la segunda el cliente disfruta de los beneficios del producto o servicio. Esta técnica fotográfica, maneja un contraste visual que impacta directamente al cerebro primitivo del ser humano.

\section{Metodología}

El universo de la población agrupa los establecimientos comerciales del Centro Comercial en las categorías de textiles, comidas, diversión y entretenimiento, libros y electrodomésticos. La muestra es de 124, teniendo en cuenta una confiabilidad del $95 \%$ y un margen de error del $5 \%$.

$z=1.96$; valor $z$ curva normal, confiabilidad $95 \%$.

$$
\begin{array}{ll}
n= & z^{2} p^{*} q{ }^{*} \\
& e^{2}(N-1)+z^{2}(p * q)
\end{array}
$$

$p=0.50 ;$ probabilidad de éxito, en donde la mitad del total de establecimientos aplica efectivamente alguna práctica de neuromarketing.

$q=0.50 ;$ probabilidad de fracaso, en donde la mitad del total de establecimientos no aplica efectivamente alguna práctica de neuromarketing.

$\mathrm{N}=182$; población, número total de establecimientos dentro del Centro Comercial.

$E=0.05$; margen de error $5 \%$ determinado.

$\mathrm{n}=124$ establecimientos comerciales, muestra obtenida para elaborar el diagnóstico.
La muestra de 124 establecimientos comerciales fue estratificada de acuerdo con cada categoría: textiles (71), comidas (25), electrodomésticos (12), diversión y entretenimiento (11) y libros (5). El instrumento aplicado comprende dos dimensiones: contexto externo y contexto interno. Cada dimensión tiene un conjunto de variables e indicadores, que están relacionados con la teoría del neuromarketing (Tabla 3) ya analizadas en el marco teórico. Se señala que la observación se realizó en horario nocturno, atendiendo a que en estas horas el Centro Comercial recibe el mayor número de

\begin{tabular}{|c|c|c|}
\hline \multirow[b]{2}{*}{ Variable } & \multicolumn{2}{|c|}{ Dimensión: contexto externo } \\
\hline & Indicador & Descriptor \\
\hline \multirow[t]{4}{*}{ Imagen } & Tamaño & $\begin{array}{l}\text { D1. Las imágenes del establecimiento } \\
\text { son grandes y llamativas. }\end{array}$ \\
\hline & Luz & D2. Presencia de luz en el exterior de \\
\hline & & $\begin{array}{l}\text { los establecimientos comerciales que } \\
\text { resalta los colores. }\end{array}$ \\
\hline & Color & $\begin{array}{l}\text { D3. Uso de colores predominantes en } \\
\text { el exterior de los establecimientos: } \\
\text { amarillo, rojo, azul, verde, naranja, } \\
\text { rosa, violeta, negro. }\end{array}$ \\
\hline \multirow{3}{*}{$\begin{array}{l}\text { Exhibición } \\
\text { de los } \\
\text { productos } \\
\text { Marca }\end{array}$} & Luz & $\begin{array}{l}\text { D4. Los productos son resaltados con } \\
\text { luz lo que permite su realce. }\end{array}$ \\
\hline & Tamaño & $\begin{array}{l}\text { D5. La marca es grande y visible } \\
\text { para el público a larga distancia } \\
\text { (aprox. } 15 \mathrm{~m} \text { ). }\end{array}$ \\
\hline & Color & $\begin{array}{l}\text { D6. La marca es resaltada por una luz } \\
\text { produciendo un efecto visual para el } \\
\text { transeúnte. } \\
\text { D7. Los colores son llamativos. }\end{array}$ \\
\hline & \multicolumn{2}{|c|}{ Dimensión: contexto interno } \\
\hline Variable & Indicador & Descriptor \\
\hline \multirow{3}{*}{$\begin{array}{l}\text { Elementos } \\
\text { del } \\
\text { espacio } \\
\text { (Imagen) }\end{array}$} & Tamaño & $\begin{array}{l}\text { D8. El establecimiento es amplio y } \\
\text { ofrece espacio al cliente para su } \\
\text { recorrido. }\end{array}$ \\
\hline & Luz & $\begin{array}{l}\text { D9. El lugar está lo suficientemente } \\
\text { iluminado lo que le permite al cliente } \\
\text { detallar cada elemento al interior del } \\
\text { establecimiento. }\end{array}$ \\
\hline & Temática & $\begin{array}{l}\text { D10. Los colores del establecimiento } \\
\text { son llamativos para lo cual utiliza } \\
\text { preferiblemente el color amarillo, } \\
\text { azul, rojo, verde, rosa, violeta y negro. } \\
\text { D11. El establecimiento presenta una } \\
\text { temática específica acorde con su } \\
\text { objeto social. } \\
\text { D12. Las imágenes que decoran el } \\
\text { establecimiento son visibles. }\end{array}$ \\
\hline \multirow[t]{2}{*}{$\begin{array}{l}\text { Exhibición } \\
\text { de los } \\
\text { productos } \\
\text { (Imagen) }\end{array}$} & Orden & $\begin{array}{l}\text { D13. Los productos del establecimien- } \\
\text { tos están ordenados por categorías o } \\
\text { criterio que permiten fácilmente su } \\
\text { ubicación. }\end{array}$ \\
\hline & Cantidad & $\begin{array}{l}\text { D14. Los productos están expuestos } \\
\text { en cantidades que permite captar la } \\
\text { atención de los clientes evitando } \\
\text { dispersarla por la acumulación } \\
\text { excesiva de los mismos. }\end{array}$ \\
\hline & & Fuente: Avendaño, W.R. (2013). \\
\hline
\end{tabular}
visitantes. 


\section{Resultados y discusión}

\subsection{Contexto visual externo de los establecimientos del Centro Comercial Ventura Plaza}

\begin{tabular}{|c|c|c|c|c|c|c|c|}
\hline Variable & Indicador & Descriptor & \multicolumn{5}{|c|}{ Categoría del establecimiento } \\
\hline \multirow[t]{7}{*}{ Imagen } & Tamaño & D1. & $54(76 \%)$ & $25(100 \%)$ & $9(81.8 \%)$ & $4(80 \%)$ & $10(83.3 \%)$ \\
\hline & Color & D3. Amarillo & $18(25.3 \%)$ & $20(80 \%)$ & $545.4 \%)$ & $3(60 \%)$ & $4(33.3 \%)$ \\
\hline & & D3. Rojo & $8(11.2 \%)$ & $16(64 \%)$ & $6(54.5)$ & $2(40 \%)$ & $6(50 \%)$ \\
\hline & & D3. Azul & $9(12.6 \%)$ & $1(4 \%)$ & $436.3 \%)$ & $1(20 \%)$ & $5(41.6 \%)$ \\
\hline & & D3. Verde & $6(8.4 \%)$ & $1(4 \%)$ & $3(27.2 \%)$ & 0 & 0 \\
\hline & & D3. Naranja & $11(15.4 \%)$ & $2(8 \%)$ & $545.4 \%)$ & $1(20 \%)$ & $1(8.3 \%)$ \\
\hline & & D3. Negro & $10(14 \%)$ & $2(8 \%)$ & $218.1 \%)$ & $2(40 \%)$ & $2(16.6 \%)$ \\
\hline \multirow{4}{*}{$\begin{array}{l}\text { Exhibición de los productos } \\
\text { Marca }\end{array}$} & Luz & D4. & $17(23.9 \%)$ & $23(92 \%)$ & $10(90.9 \%)$ & $1(20 \%)$ & 0 \\
\hline & Tamaño & $\mathrm{D}_{5}$. & $51(71.8 \%)$ & $25(100 \%)$ & $11(100 \%)$ & $4(80 \%)$ & $10(83.3 \%)$ \\
\hline & Luz & D6. & $17(23.9 \%)$ & $20(80 \%)$ & $11(100 \%)$ & $3(60 \%)$ & $10(83.3 \%)$ \\
\hline & Color & D7. & $55(77.4 \%)$ & $24(96 \%)$ & $11(100 \%)$ & $4(80 \%)$ & $10(83.3 \%)$ \\
\hline
\end{tabular}

En la dimensión contexto externo de los establecimientos, se examinó en horario nocturno las variables imagen, exhibición de productos y marca a través de los indicadores luz, color y tamaño. Los resultados evidencian por categorías de establecimientos (Tabla 4):

* Textiles: las imágenes utilizadas son predominantemente grandes y hace uso de luz sobre ellas, aunque en menor medida que otro tipo de establecimientos a excepción de las librerías. Los colores utilizados por lo general son amarillo y naranja, es decir, que buscan generar un ambiente natural, un mayor impacto sobre los visitantes buscando activar emociones como la alegría y la acción para que los potenciales clientes ingresen al establecimiento, en especial las personas adultas con edades superiores a los 40 años. Es recomendable hacer uso del color verde por dos razones: (i) sigue manteniendo el ambiente natural, (ii) permite atraer a los jóvenes, quienes son un segmento de mercado importante debido a su permanencia dentro del centro comercial. El color de la marca es acorde con el tipo de establecimiento porque predominan los amarillos, el naranja y el negro, este último realza los demás colores del espacio externo. Es recomendable generar luz sobre la marca para resaltar el concepto que se quiere transmitir: moda, seducción, acción, elegancia.

* Comidas: El tamaño de las imágenes exteriores son grandes en todos los establecimientos a fin de mos- trar al visitante el tipo de productos que se ofertan. Asimismo, se utiliza la luz por lo general para resaltar las imágenes de los productos. Predomina los colores amarillo y rojo, produciendo saciedad y hambre. Por otro lado, el amarillo evoca productos saludables y el rojo atrae al mercado joven. La marca es grande en todos los establecimientos, se proyecta con luz para generar una mayor visibilidad y los colores utilizados son acordes (amarillo y rojo).

* Diversión y entretenimiento: Las imágenes son grandes y visibles debido al uso predominante de la luz. Utilizan de forma combinada de los colores rojo, amarillo, naranja, azul y verde, donde predomina el primero y se ausenta o se disminuye el uso del último. Son colores acorde con el tipo de establecimiento porque evocan alegría, vacaciones, acción y aumento del tamaño de las imágenes al hacer uso del amarillo. Por otro lado, el color rojo se usa en ambientes como sala de cine o teatros, lo cual es propio para actividades de ocio y tiempo libre. El verde estimula la imaginación y la creatividad, y el naranja evoca festividad, lo cual es coherente con el tipo de establecimiento. Los productos de estos establecimientos (máquinas, juegos, cine) están muy bien iluminados y la marca es resaltada por el tamaño, el color y la luz proyectada.

* Libros: Las imágenes de estos establecimientos son grandes por lo general en la parte externa, pero no se utiliza la luz para resaltar las mismas, lo cual 
disminuye el efecto de atención del visitante. Predomina el uso del color amarillo y rojo, no coherente con el tipo de establecimiento. Se recomienda en este caso el uso del color azul porque produce en el visitante atención, calma, disminución de la tensión muscular y nerviosa. Asimismo, este color se asocia con la comunicación, los medios y la escritura. Es posible combinarlo con el verde para estimular la creatividad y la innovación. La luz del escenario externo es reducida sobre los productos, y se debe incrementar. La marca tiene por lo general un buen tamaño y un color adecuado, pero es limitada por el uso de la luz, la cual se debe utilizar en mayor medida.

* Electrodomésticos: La imagen de los establecimientos de electrodomésticos son grandes es su mayoría pero solo algunos iluminan las imágenes disponibles. Los colores de mayor uso en las imágenes son el rojo, el azul y el amarillo. Muy pocos hacen uso del color negro y naranja. Estos colores no son recomendables; atendiendo a las características de estos establecimientos, es preferible el uso del verde que connota innovación y el gris que está asociado con productos duraderos, fiables, de alto valor, útiles y sofisticados. La luz no se utiliza para la exhibición de productos pero sí para resaltar la marca.

\subsection{Contexto visual interno de los establecimientos del Centro Comercial Ventura Plaza}

En el ámbito del contexto visual interno de los establecimientos observados en el Centro Comercial Ventura Plaza, se analizaron: (i) los elementos del espacio a través de los indicadores tamaño, luz, color y temática; (ii) la exhibición de los productos con los indicadores orden y cantidad. Las evidencias permiten hacer las siguientes apreciaciones y recomendaciones atendiendo el tipo de establecimiento comercial (Tabla 5):

\begin{tabular}{|c|c|c|c|c|c|c|c|}
\hline Variable & Indicador & Descriptor & \multicolumn{5}{|c|}{ Categoría del establecimiento } \\
\hline \multirow{4}{*}{$\begin{array}{l}\text { Elementos del espacio } \\
\text { (Imagen) }\end{array}$} & Tamaño & D8. & $61(85.9 \%)$ & $4(16 \%)$ & $11(100 \%)$ & $5(100 \%)$ & $12(100 \%)$ \\
\hline & Color & D10. & $57(80.2 \%)$ & $23(92 \%)$ & $11(100 \%)$ & $4(80 \%)$ & $10(83.3 \%)$ \\
\hline & Temática & D11. & $62(87.3 \%)$ & $21(84 \%)$ & $11(100 \%)$ & $5(100 \%)$ & $9(75 \%)$ \\
\hline & & D12. & $65(91.5 \%)$ & $25(100 \%)$ & $11(100 \%)$ & $5(100 \%)$ & $9(75 \%)$ \\
\hline \multirow{2}{*}{$\begin{array}{l}\text { Exhibición de los productos } \\
\text { (Imagen) }\end{array}$} & Orden & D13. & $64(90.1 \%)$ & $25(100 \%)$ & $8(72.7 \%)$ & $5(100 \%)$ & $6(50 \%)$ \\
\hline & Cantidad & D14. & $49(69 \%)$ & $18(72 \%)$ & $10(90.9 \%)$ & $4(80 \%)$ & $9(75 \%)$ \\
\hline
\end{tabular}

* Textiles: El espacio de los establecimientos por lo general son amplios pero los colores y la luz se utilizan en menor medida. El rojo y el azul deberían ser los de mayor uso atendiendo a que vincula tanto a hombres como mujeres, y opcionalmente el uso del color verde. En estos establecimientos predomina el color blanco lo cual evita que se resalte las prendas de vestir. Es positivo el uso de las temáticas e imágenes al interior de los establecimientos. Por otro lado, la exhibición de los productos está dada por categorías y cerca de la mitad procura mostrar los productos de forma ordenada evitando la acumulación exagerada. Es recomendable el uso de luces para exhibir los productos y el lugar.

* Comidas: Los establecimientos de comida por lo general no cuentan con espacio privado para la atención de los clientes, porque hay una amplia plazoleta para el consumo de alimentos. Sólo $16 \%$ cuenta con un espacio propio. De este modo, la luz utilizada es la que se observa en la zona de atención y que ilumina en mayor medida la imagen de los productos. El color diferencia cada negocio y predomina los que se describieron en la dimensión externa (punto 4.1). Los establecimientos de comidas por lo general manejan una temática y las imágenes son visibles al público. Los productos se presentan en orden atendiendo a criterios de clasificación pero tienden a acumularse en los espacios que son reducidos. Se recomienda hacer un uso acorde del espacio para la exhibición de los productos.

* Diversión y entretenimiento: Los establecimiento presentan espacios amplios, luminosos, con colores como rojo, amarillo y naranja entre otros. Todos tienen una temática específica de acuerdo con los servicios y productos que ofrecen. En algunos no se percibe un orden específico de los mismos pero no se muestran acumulados, permitiendo que la atención de los usuarios se enfoque en los elementos que más les atrae. 
* Libros: El espacio es amplio en todos los establecimientos observados pero el uso de la luz no es adecuada. Por el tipo de establecimiento es recomendable el uso de la luz para que los visitantes identifiquen y evalúen los productos exhibidos. Los colores son acordes (azul-blanco) y se manejan temáticas apropiadas. Los productos se exhiben por categoría y la cantidad es moderada, lo que permite que no se disperse la atención del cliente.

* Electrodomésticos: Los espacios son amplios y permite la comodidad de los clientes. La luz se utiliza para resaltar el espacio y los productos. Los colores predominantes son azul y verde, recomendables para este tipo de locales. Sólo $75 \%$ hace uso de temáticas e imágenes al interior, por lo que sería recomendable el uso de los mismos para evocar conceptos específicos como innovación, comodidad, seguridad, entre otros. Los productos no tienen órdenes específicos y a veces se acumulan haciendo que se disperse la atención del cliente.

\section{Conclusiones}

Los establecimientos comerciales del Centro Comercial Ventura Plaza de la ciudad de Cúcuta (Norte de Santander, Colombia) realizan algunas prácticas que están relacionadas con el neuromarketing visual. Los resultados no demuestran si estas prácticas obedecen a una planeación estratégica, pero sí evidencia que en un buen nivel, los establecimientos utilizan adecuadamente los colores y las imágenes. El uso adecuado de los principios de la percepción (color e imagen fotográfica) producen una mayor atención de los consumidores al estimular la visión. Sin embargo, los hallazgos evidencian en muchos de los establecimientos la ausencia de la luz sobre la marca o los productos. Este es un aspecto en el que pueden mejorar a fin de aumentar la competitividad y la conquista de nuevos segmentos de mercado.

El color amarillo es mayoritariamente utilizado en las categorías de comida y libros. Este tono es el que genera mayor impacto en la retina del ojo humano y con esto, psicológicamente, induce a la acción. El rojo es manejado en las categorías de comidas, diversión/ entretenimiento y electrodomésticos. Con este, se da un enfoque más emocional a las decisiones del consumidor y es punto clave para atraer al público joven.

En las categorías comerciales de textiles, comidas, diversión/entretenimiento, libros y electrodomésticos, poseen en su totalidad, una decoración acorde con los productos que ofrece al público, esto con ayuda de un espacio que hace cómodo el desplazamiento. El manejo de temáticas e imágenes influyen en la decisión de compra de los clientes. Los establecimientos comerciales en general utilizan tonalidades llamativas en su interior, lo que influye en la capacidad decisiva y emotiva de elección de los clientes.

\section{Referencias}

Alvarado, L. (2008). Neuromarketing, ciencia al servicio del conocimiento. Cuadernos de Investigación, 2 (2) (p. 7).

Barthes, R. (1986). Lo obvio y lo obtuso: Imágenes, gestos, voces. Barcelona, España: Paidós Ibérica (p. 350).

Braidot, N. (2005).Neuromarketing, neuroeconomía y negocios. Madrid, España: Puerto Norte-Sur (p. 741).

Braidot, N. (2011). Neuromarketing en acción. ¿Por qué los clientes te engañan con otros si dicen que gustan de ti? Buenos Aires, Argentina: Granica (p. 229).

Dierssen, M. (edit.). (2007). Unidad Didáctica: Viaje al Universo Neural. Madrid, España: Fundación Española para la Ciencia y la Tecnología (p. 276)

Ferrell, 0. y Hartline, M. (2006). Estrategia de Marketing. México D.F., México: Cengage Learning Editores (p. 648).

Ferrer, A. (2009). Neuromarketing, la tangibilizacion de las emociones. Tesis de Licenciado en Publicidad y Relaciones Públicas. Universitat Abat Oliba CEU, Llicenciatura en Publicitat i Relacions Públiques. Barcelona, España.

Fraser, T. y Banks, A. (2005). Color: La guía más completa. Madrid, España: Evergreen (p. 224).

García-Marza, D. (2012). Neuromarketing y neurociencia presentado en XX Congreso EBEN-España, La imagen de la empresa en el siglo XXI. Valencia, España, 20, 21 y 22 de junio. Fundación Etnor.

Guanipa, J. (2007). Discurso Publicitario de la vallas de Licor. Enfoque Semiolinguístico. Tesis de maestría. Universidad del Zulia. Maracaibo, Venezuela.

Kenning, P. \& Plasman, H. (2005). Neuroeconomics: An overview from an economics perspective. Brain Research Bulletin, (67) (pp. 343-354).

Khalfa, J. (1995). ¿Qué es la inteligencia? Madrid, España: Alianza Psicología Minor (p. 216).

Kinnear, T. y Taylor, J. (1998). Investigación de mercados: en enfoque aplicado. Bogotá, Colombia: MacGraw-Hill (p. 812).

Kotler, P. y Keller, K. (2006). Dirección de Marketing. México D.F., México: Pearson Educación (p. 816).

Malfitano, O. (2007). Neuromarketing: cerebrando negocios y servicios. Buenos Aires, Argentina: Granica (p. 328).

Morales, L. y Rivera, P. (2012). Neuromarketing: la herramienta de diferenciación de las empresas contemporáneas. Tesis de grado. Universidad del Rosario, Programa de Negocios Internacionales. Bogotá D.C., Colombia.

Pavó, J. y Hidalgo, A. (1999). Gestión e innovación: un enfoque estratégico. Madrid, España: Piramide (p. 236).

Penn, D. (2011). ¿Qué aporta la neurociencia a la investigación de mercados? Research World, (26) (pp. 66-67).

Pride, W. y Ferrell, O. (2006).Marketing: Concepts and strategies. Boston, USA: Houghton Mifflin Company (p. 610).

Renvoisé, P. y Morin, C. (2007). Neuromarketing. Understanding the Buy Button in Your Customer's Brain. Nashville, USA: Sales Brain LLC (p. 243).

Russell, D. (1990a). El Libro del amarillo. Madrid, España: Gustavo Gili (p. 144).

Russell, D. (199ob). El Libro del azul. Madrid, España: Gustavo Gili (p. 144).

Russell, D. (1990c). El Libro del rojo. Madrid, España: Gustavo Gili (p. 144). 
Russell, De. (1990d). El Libro del blanco y negro. Madrid, España: Gustavo Gili (p. 144).

Salazar, C. (2011). La neurociencia del consumidor como horizonte de investigación, conceptos y aplicaciones. Un enfoque paradigmático. Revista Universidad \& Empresa, (21) (pp. 143-166).
Tamblay, M. E. (2011). Viaje al centro de la mente del consumidor. Nuestro Tiempo, (670) (pp. 32-39).

Vera, C. (2010). Generación de impacto en la publicidad exterior a través del uso de los principios del neuromarketing visual. Telos, 12 (2) (pp. 155-174).

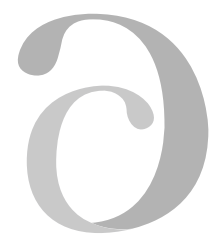

Cuadernos de Administración / Facultad de Ciencias de la Administración / Universidad del Valle Periodicidad: semestral / ISSN impreso Nº 0120-4645 - ISSN electrónico N²256-5078 / Nombre abreviado: cuad.adm. Edición Vol. $29 \mathrm{~N}^{\circ} 49$ (enero - junio de 2013)

Un caso práctico para el análisis del neuromarketing visual en el Centro Comercial Ventura Plaza (Cúcuta, Colombia)/ William R. Avendaño Castro 